\title{
SOLAR ATMOSPHERIC JET PROPAGATION IN A VORTEX FIELD
}

\author{
Yu. P. Ladikov-Roev, S. O. Cheremnykh(D), A. D. Voitsekhovska(D), Yu. O. Selivanov (D) \\ Space Research Institute of NASU \& SSAU, \\ 40, Glushkov Ave., build. 4/1, \\ Kyiv, UA-03680, Ukraine \\ e-mail: yuraslv@gmail.com \\ (Received 01 July 2020; in final form 08 September 2020; accepted 16 October 2020; published online 04 March 2021)
}

\begin{abstract}
On the assumption of the existence of a vortex layer in the solar atmosphere, the interaction of chromospheric jets with individual vortices is studied. Although all the models assume a penetration of the jet into a quiet atmosphere, however, perturbations caused by the rise and fall of a multitude of jets cannot fail to cause vortex flows in a differentially rotating solar atmosphere, as occurs in the case of hurricanes and tornadoes on the Earth. When interacting with a jet, the vortex can create thrust applied to the jet and directed upwards. The thrust complements the action of the initial pulse on the jet and the same elevation height can be achieved with lower initial velocities. Due to the action of the vortex, the jet rises both higher and during a longer time than, for example, in the case of a ballistic mechanism only. A jet, when it penetrates the vortex, can expand due to the centrifugal acceleration caused by this vortex. Both effects can modify the movement of the jets and, therefore, can contribute to the fine structure of the solar wind.
\end{abstract}

Key words: Solar physics, magnetohydrodynamics, jets, vortices.

DOI: https://doi.org/10.30970/jps.25.1902

\section{INTRODUCTION}

Ongoing space missions, such as the Parker Solar Probe, Solar Orbiter, will provide information on the subtle variations in the plasma flow that makes up the solar wind (e.g., $[1,2])$. There is no doubt that a significant contribution to this stream is made by linear structures of various scales, from spicules [3] to coronal jets [4], literally flashing the atmosphere of the Sun [5]. Also, one should not forget about the influence of vortices [6]. Important in themselves, they, as we show below, can affect the nature of the indicated linear structures' contribution to the variations of the solar wind near the Sun.

We must have a mechanism for interpreting such near-solar measurements. Obviously, powerful computer models provide the basis for the interpretation of the measurement data (e.g., [7]). However, such models are rather slow and do not provide an operational interpretation in physics of what is happening. This interpretation can be provided by simple analytical models of the basic phenomena occurring in the solar atmosphere.

Linear movements, such as jets, are a common phenomenon in the solar atmosphere, from X-ray jets on the largest scale down to chromospheric spicules on the subarcsecond scale. They have been implicated in playing a substantial role in the energy and mass balance of the chromosphere, transition region, and corona of the Sun, but the process of their formation is still not well understood in detail [8, 9].

Probably the main difficulty is that it is not always possible to continuously observe the entire movement of the jet, from its appearance to its greatest rise. An obstacle to this may be the lack of contrast relative to the background, as well as a change in the temperature of the jet as it rises, due to which the spectral maximum of its glow shifts from the spectral line used in observations [4]. Finally, as in the case of spicules, the density of their distribution over the surface of the Sun simply makes it impossible to observe the initial stage of their movement.

In sum, when studying jets in the solar atmosphere, we must take into account the following conditions, which in their combination are important in the interpretation of observations: (1) gravitational stratification of the solar atmosphere; (2) mostly monotonous increase in temperature with height; (3) the correspondence of the emission lines of chemical elements to certain ranges of temperatures and, therefore, to certain ranges of heights; (4) in the chromosphere, plasma motions dominate the magnetic field in the lower part and below, whereas the magnetic field dominates the dynamics in the upper one and above.

Despite the fact that there is no confidence in the mechanism of launching jets, although there are a number of relevant proposals $[3,10,11]$, the stages of their movement into the corona region are rather confidently modeled and explained based on the interpretation of observations. On the other hand, with a realistic measurement cadence of a dozen seconds, we get information about the jet at displacements of the order of 0.5-1.5 Mm, i. e., of the order of 1 arcsec. In many cases this is not enough. In particular, it is difficult to find the answer to the question at which characteristic speed the jets enter the chromosphere from the photosphere, although this is important if one is building a model of such a jet.

Theoretical models of jets dynamics, developed to date, may be grouped into three categories (see e.g. $[12,13]):(1)$ Shocked matter flowing behind vertically propagating shock fronts; (2) Jets driven upwards along magnetic field lines by hydrostatic and hydrodynamic pressure forces; (3) Matter accelerated by magnetic 
forces. Without going into a detailed analysis of these models, we will only mention that none of the models is fully adequate. For example, the hypothesis of ballistic initialization of spicules, which was considered earlier, is not entirely adequate. Indeed, spicules, which reached the height of $12000 \mathrm{~km}$ on a ballistic trajectory, require a starting speed of $73.5 \mathrm{~km} \mathrm{~s}^{-1}$ at the height of $2000 \mathrm{~km}$ that contradicts the observed value, which is $25 \mathrm{~km} \mathrm{~s}^{-1}$. However, as the beginning of the individual history of most chromospheric jets is in the photosphere, a recent paper is interestiong [11], whose authors applied sophisticated mathematics to solar data and showed convincingly that the colliding horizontal flows play a decisive role in the photospheric jets formation. They claim that the matter in the jets moves almost in the vertical direction with a slight expansion of the flow in the upper layers. The authors concluded that these two facts may indicate a helical structure of the magnetic field lines of the tubes, which increases their resistance to dynamic disturbances from the environment. Thus, sufficiently clear data were obtained on the physical state of at least some jets penetrating the chromosphere.

And although most of the currently recognized dynamic structures in the solar atmosphere are spiraling flows of various kinds, in particular swirling magnetic flux tubes, where linear motion is combined with the rotational one, nevertheless, important features of their behavior can be derived from a simple analytical representation where only a vortex and a linear jet are interacting. Namely, we consider the basic effects due to the interaction of a jet with a vortex external to it and show that this can lead to significant changes in the behavior of the jet. In our opinion, the proposed mechanism can be combined with various models of the initiation of jets in the solar atmosphere.

It should be noted that our interest in vortices was stimulated by both the long history of research into the properties of plasma vortex formations by several of us [14-20] and a number of successful studies, which have demonstrated the existence of vortex formations in subsurface and above-surface layers of the Sun [21-24]. It is important that there are papers [21-23] supporting the idea that one can assume the existence of vortices of various sizes in the Sun's chromosphere, and offering some mechanisms of the generation of such vortices. At last, in a recent paper [25], its authors concluded that their observations "show two long-lived structures of plasma that each rotate clockwise inside a $10 \operatorname{arcsec}^{2}$ quiet-Sun region. Their circular polarisation signals are five to ten times above the noise level".

It should also be mentioned that Nakariakov et al. [26] described a mechanism of the generation of a sequence of vortices, the Karman vortex street. Also, Pashitsky [27] theoretically linked the nonzero vorticity of the chromospheric plasma (caused by the rotation of the Sun) and the increase in the axial velocity of some ascending plasma flow with the creation of MHD vortex and further acceleration of its rotation, similar to the mechanism of formation of airborne eddies in the Earth's atmosphere (such as tornadoes and typhoons). The addi- tional condition for the vertical velocity of the plasma flow is important here, since it is known that the vorticity created only by the rotation of the Sun is weak.

Likewise, we have to mention the original work by $\mathrm{Ki}-$ votides [28], in which the interactions between vortex tubes and magnetic-flux rings in incompressible MHD are investigated using computer code at high kinetic and magnetic Reynolds numbers, and over a wide range of the interaction parameter, which is a measure of the strength of the Lorentz force in units of the inertial force. On the assumption that the tubes are vortex tubes, extremely complex scenarios of interaction with the external vortex ring were obtained, which ultimately boiled down to the interlacing of both objects and the formation of secondary rings.

In this paper, we sought to study some of the basic features of the possible interaction of a solar atmospheric jet and a vortex without going into detail, which at this stage of research can be taken as insignificant. As a result, we obtain an additional lifting force acting on the jet and modifying its dynamics.

Finally, it should be added that the problem of the interrelation between the complexity and adequacy of models as such is intensively discussed in the modeling community. So, following the authors of [29], we want to quote statistician George E. P. Box, who observed in 1987 that "all models are wrong but some are useful" and accept their conclusion that "simpler models enable scientists ... to understand how assumptions and outputs are linked."

\section{RISE OF A JET IN A VORTEX FIELD}

In the article, we assume that a jet is a cylinder of magnetised plasma of limited dimensions: radius $a$, height $l$, such that $a / l \ll 1$, in other words, it is the magnetic flux tube that comes out of the solar surface and is bounded from above. Let us assume that the plasma density inside and outside the cylinder is $\rho_{0 i}$ and $\rho_{0 e}$, respectively; then according to the experimental data (e.g., [7]), the relation $\mu_{0}=\rho_{0 e} / \rho_{0 i}<1$ is satisfied. Note that under the conditions of the real chromosphere, this ratio can have values of 0.1 or less.

We also assume that at the initial time, $t=0$, such a plasma cylinder gains a momentum $I=\rho_{0 i} u$, which causes it to move up, into the chromosphere, in which we assume the presence of a vortex layer, which contains whirlwinds moving in it horizontally. One of these vortices can be above the upper end of the cylinder (see Fig. 1). For a greater clarity of the presentation of the idea, we will not go into detail of the vortex's origin.

We show that if a vortex is located directly above the upper surface of the cylinder, there is a lifting force acti$\mathrm{ng}$ on it. This action is combined with the rise due to the initial pulse $I$. Further, taking into account the results of paper [11] cited above, we assume, in the first approximation, that the jet moves as a rigid body. We define the state of stress at the ends using the assumption that the center of the vortex coincides with the center of the 
cylinder. Then the velocity of the rotation is $V_{\varphi}=\Omega r$, where $\Omega$ is the angular velocity. This gives the pressure rise in accordance with the equation

$$
\frac{d p}{d r}=\frac{\rho_{0 e} V_{\varphi}^{2}}{r}=\rho_{0 e} \Omega^{2} r
$$

hence

$$
p=\frac{\rho_{0 e} \Omega^{2} r^{2}}{2}+p_{0}
$$

Here $p_{0}$ is the pressure inside the plasma tube. According to Eq. (2), the pressure inside the vortex is determined by the centrifugal force, which always causes a rarefaction of the atmospheric environment. The pressure force (or tension) which acts on the top of the cylinder is

$$
\int_{0}^{a} 2 \pi r\left[\rho_{0 e} \frac{\Omega^{2} r^{2}}{2}+p_{0}\right] d r=2 \pi \rho_{0 e} \frac{\Omega^{2} a^{4}}{8}+p_{0} S
$$

Here $S=\pi a^{2}$ is the area of the plasma cylinder crosssection.

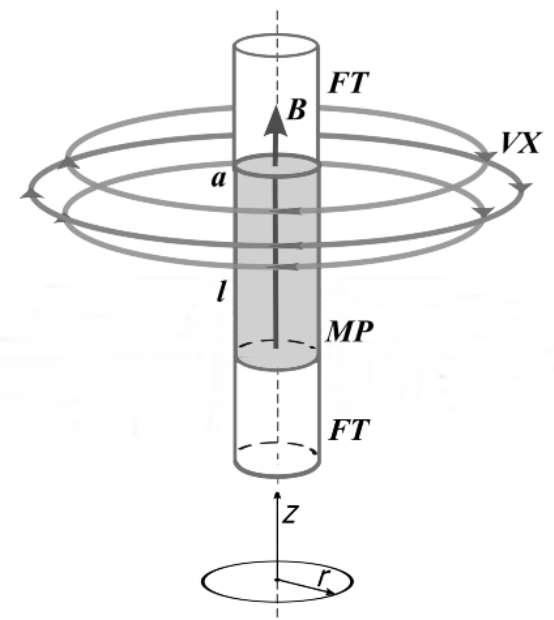

Fig. 1. Simplified model of the jet as a cylinder of magnetised plasma (MP) of limited dimensions: $a$ is a radius and $l$ is height of cylinder, which moves inside a flux tube (FT) with magnetic field $(B)$ through the external vortex $(\mathrm{VX})$ with a speed in $z$ direction

By considering a jet to be a solid body of mass $M_{\mathrm{J}}=$ $\rho_{0 i} S l$, taking into account the force of gravity and the tensions from above and below acting on it, we obtain the equation

$$
M_{\mathrm{J}} \frac{d V_{z}}{d t}=-M_{\mathrm{J}} g_{\mathrm{S}}-p_{0} S+2 \pi \rho_{0 e} \frac{\Omega^{2} a^{4}}{8}+p_{0} S
$$

from which we obtain

$$
V_{z}=-g_{\mathrm{S}} t+\mu_{0} \frac{\Omega^{2} a^{2}}{4 l} t+u .
$$

The time of the jet rising, $t_{\mathrm{r}}\left(\right.$ i. e. $V_{z}\left(t_{\mathrm{r}}\right)=0$ ), is

$$
t_{\mathrm{r}}=\frac{u}{g_{\mathrm{S}}-\mu_{0} \frac{\Omega^{2} a^{2}}{4 l}} .
$$

Assuming that $V_{z}=d z / d t$ and integrating, we find

$$
z=u t-\left(g_{\mathrm{S}}-\mu_{0} \frac{\Omega^{2} a^{2}}{4 l}\right) \frac{t^{2}}{2} .
$$

Substituting $t=t_{\mathrm{r}}$ we find the height of rising, $z=h$, modified by a vortex

$$
h=\frac{u^{2}}{2\left(g_{\mathrm{S}}-\mu_{0} \frac{\Omega^{2} a^{2}}{4 l}\right)} .
$$

Thus, the vortex, bumping into the jet, which is rising up due to the initial pulse, lifts it to a higher altitude and makes this for a longer time. The height and the time increase further with an increase in $\Omega$ and depend on the ratio between the external and internal densities, decreasing for "heavy" jets.

To illustrate the described effects, let us consider models of a jet with parameters that are considered typical of the chromosphere.

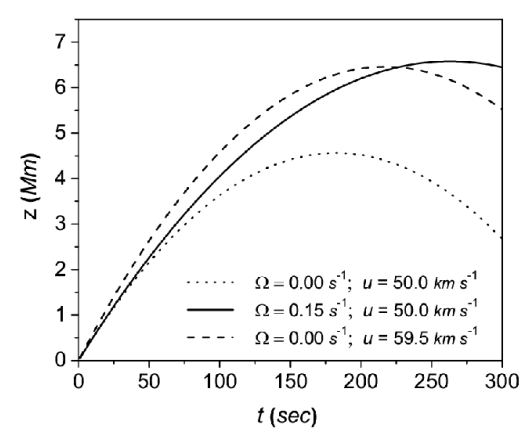

Fig. 2. Altitude of jet, $z$, vs rising time $t$. We have shown three cases for different initial speeds $u$, and vortex's angular velocity $\Omega$. Here $a=300 \mathrm{~km}, l=6000 \mathrm{~km}, g_{\mathrm{S}}=274 \mathrm{~ms}^{-2}$, $\mu_{0}=1$.

We can see from Fig. 2, plotted at $\mu_{0}=1$ as the limiting case, that the thrust created by the vortex complements the action of the initial pulse and the same elevation height can be achieved at lower initial velocities. Note that $V_{\varphi}=30 \mathrm{~km} / \mathrm{s}$ for $\Omega=0.15 \mathrm{~s}^{-1}$ is compatible with the sound speed in the plasma outside of the jet.

\section{EFFECT OF VORTICITY ON THE LATERAL SURFACE OF THE JETS}

For a qualitative analysis let us restrict ourselves also in this case to a simple model of the influence of the vortex media on a magnetic flux tube. Let us consider a plasma cylinder of infinite height with a radius $a$, containing a constant vertical magnetic field $B_{z}=\mathbf{B}_{0} \mathbf{e}_{z}$, surrounded by a plasma in rotation at a frequency $\Omega$, and experiencing radial perturbations $\xi_{r}$, i.e. assuming that the cylinder is immersed in a vortex (see Fig. 3 ). Hereafter we will use a special normalisation for a magnetic field, $B$, and electric current, $j$ :

$$
B=B^{*} \sqrt{4 \pi}, \quad j=\frac{c j^{*}}{\sqrt{4 \pi}} .
$$


Later in the text, we omitted symbol $\left({ }^{*}\right)$ in transformed variables. We assume then that, in zero approximation, the plasma in the cylinder is at rest and has a density $\rho_{i 0}$ and a pressure $p_{i 0}$. Suppose further that outside the cylinder, i. e. $r \geq a$, there is a rotational movement $V_{\varphi}=$ $\Omega a^{2} / r$. In this case, the pressure outside the cylinder is equal to

$$
p_{e 0}=\hat{p}_{e 0}-\rho_{e 0} \frac{\Omega^{2} a^{4}}{2 r^{2}},
$$

and, respectively, the pressure inside the cylinder is equal to

$$
p_{i 0}=\hat{p}_{i 0}+\frac{B_{0}^{2}}{2} .
$$

Here $\hat{p}_{i 0}$ and $\hat{p}_{e 0}$ are unperturbed pressures inside and outside of the plasma cylinder, respectively. At the boundary of the plasma cylinder, i. e. $r=a$, the values of the pressure inside and outside the cylinder must be equal, i.e. $p_{i 0}=p_{e 0}$. Therefore,

$$
\hat{p}_{i 0}+\frac{B_{0}^{2}}{2}=\hat{p}_{e 0}-\rho_{e 0} \frac{\Omega^{2} a^{2}}{2} .
$$

For convenience, we will further measure the pressure based on the outside pressure, $p_{e 0}$. Let us define

$$
\hat{p}_{i 0}-\hat{p}_{e 0}=\Pi_{0},
$$

where,

$$
\Pi_{0}=\frac{B_{0}^{2}}{2}+\rho_{e 0} \frac{\Omega^{2} a^{2}}{2} .
$$

Assume now that the cylinder is experiencing radial perturbations changing its surface. We consider perturbations in the liner approximation only. Thus, both inside and outside the cylinder there is a change in the density and pressure. For $r \leq a$ :

$$
\begin{aligned}
p_{i} & =-\Pi_{0}+\tilde{p}_{i}, \\
\rho_{i} & =\rho_{i 0}+\tilde{\rho}_{e}
\end{aligned}
$$

and for $r \geq a$

$$
\begin{aligned}
& p_{e}=-\rho_{e 0} \frac{\Omega^{2} a^{4}}{2 r^{2}}+\tilde{p}_{e}, \\
& \rho_{e}=\rho_{e 0}+\tilde{\rho}_{i}
\end{aligned}
$$

where $\tilde{p}_{i}, \tilde{p}_{e}$ and $\tilde{\rho}_{i}, \tilde{\rho}_{e}$ are the pressure and density perturbations inside and outside the plasma column, respectively. In addition, the displacement $\xi_{r}$ gives rise to an induced magnetic field, $\mathbf{b}$, and induced current $j_{\varphi}$ (see Fig. 3). It is clear that these perturbations must satisfy the equations of magneto-hydrodynamics (e.g., [16]). For $r \leq a$ :

$$
\begin{aligned}
& \rho_{i 0} \frac{\partial \tilde{V}_{r}}{\partial t}=-\frac{\partial p}{\partial r}+j_{\varphi} B_{z}, \\
& \frac{\partial \tilde{\rho}}{\partial t}=\rho_{i 0}\left(\frac{\partial \tilde{V}_{r}}{\partial r}+\frac{1}{r} \tilde{V}_{r}\right), \\
& \frac{\partial \tilde{p}}{\partial t}=-\gamma \Pi_{0}\left(\frac{\partial \tilde{V}_{r}}{\partial r}+\frac{1}{r} \tilde{V}_{r}\right), \\
& \frac{\partial \mathbf{b}}{\partial t}=\nabla \times[\tilde{\mathbf{V}} \times \mathbf{B}], \\
& j_{\varphi}=[\nabla \times \mathbf{b}]_{\varphi} .
\end{aligned}
$$

For $r \geq a$ :

$$
\begin{aligned}
& \rho_{e 0}\left[\frac{\partial \tilde{V}_{r}}{\partial t}-\frac{2\left(V_{0 \varphi} \tilde{V}_{\varphi}\right)}{r}\right]-\hat{\rho} \frac{V_{0 \varphi}^{2}}{2}=-\frac{\partial \tilde{p}}{\partial r}, \\
& \rho_{e 0}\left[\frac{\partial \tilde{V}_{\varphi}}{\partial t}+\hat{V}_{r} \frac{\partial V_{0 \varphi}}{\partial r}+\frac{\tilde{V}_{r} V_{0 \varphi}}{r}\right]=0, \\
& \frac{\partial \tilde{\rho}}{\partial t}+\rho_{0 e}\left(\frac{\partial \tilde{V}_{r}}{\partial r}+\frac{\tilde{V}_{r}}{r}\right)=0, \\
& \frac{\partial \tilde{p}}{\partial t}+\tilde{V}_{r} \frac{\partial}{\partial r}\left(-\rho_{0 e} \frac{\Omega^{2} a^{4}}{2 r^{2}}\right) \\
& -\gamma \rho_{0 e} \frac{\Omega^{2} a^{4}}{2 r^{2}}\left(\frac{\partial \tilde{V}_{r}}{\partial r}+\frac{\tilde{V}_{r}}{r}\right)=0 .
\end{aligned}
$$

Here $\gamma=c_{\mathrm{P}} / c_{\mathrm{V}}$ is the adiabatic index and $c_{\mathrm{P}}, c_{\mathrm{V}}$ are the specific heat capacities at constant pressure and volume, respectively. Now let us transform Eqs. (15)-(16) to a dimensionless form. Let us put

$$
\begin{aligned}
& \tilde{\rho}=\rho_{0 e} \rho, \quad \tilde{p}=\rho_{0 e} a^{2} \Omega^{2} p, \quad \tilde{\mathbf{V}}=\Omega a \mathbf{V}, \quad \xi \leftarrow a \xi, \\
& t=\frac{1}{\Omega} \tau, \quad r=a x, \quad \frac{\rho_{0 i}}{\rho_{0 e}}=\mu, \quad \frac{B^{2}}{2 \rho_{0 e} a^{2} \Omega^{2}}=A .
\end{aligned}
$$

Equations (16) in a dimensionless form, given that $\tilde{V}_{r}=$ $\partial \xi_{r} / \partial t$, take the form

$$
\begin{aligned}
& \mu \frac{\partial^{2} \xi_{r}}{\partial \tau^{2}}=-\frac{\partial p}{\partial x}+A\left[\frac{\partial^{2} \xi_{r}}{\partial x^{2}}+\frac{1}{x} \frac{\partial \xi_{r}}{\partial x}-\frac{1}{x^{2}} \xi_{r}\right], \\
& \rho+\mu\left[\frac{\partial \xi_{r}}{\partial x}+\frac{\xi_{r}}{x}\right]=0 \\
& p+\frac{\gamma}{2}(A+1)\left[\frac{\partial \xi_{r}}{\partial x}+\frac{\xi_{r}}{x}\right]=0 .
\end{aligned}
$$

After the substitution of Eq. (19) into Eq. (18) we obtain a single equation

$$
\begin{aligned}
\frac{\partial^{2} \xi_{r}}{\partial \tau^{2}} & =\frac{1}{\mu}\left[A\left(1-\frac{\gamma}{2}\right)-\frac{\gamma}{2}\right] \\
& \times\left[\frac{\partial^{2} \xi_{r}}{\partial x^{2}}+\frac{1}{x} \frac{\partial \xi_{r}}{\partial x}-\frac{1}{x^{2}} \xi_{r}\right] .
\end{aligned}
$$

By separating variables and assuming that $\xi_{r}=$ $T(\tau) \Phi(x)$, we obtain the following system of equations:

$$
\begin{aligned}
& \frac{d^{2} T}{d \tau^{2}}-\delta^{2} T=0, \\
& \frac{d^{2} \Phi}{d x^{2}}+\frac{1}{x} \frac{d \Phi}{d x}+\left[\frac{\delta^{2}}{\beta^{2}}-\frac{1}{x^{2}}\right] \Phi=0, \\
& \beta^{2}=\frac{1}{\mu}\left[\frac{\gamma}{2}-A\left(1-\frac{\gamma}{2}\right)\right] .
\end{aligned}
$$

Finally, we obtain

$$
\begin{aligned}
& \xi_{r}=C_{1} \sinh (\delta \tau) J_{1}\left(\frac{\delta}{\beta} x\right), \\
& p=C_{1} \frac{\gamma}{2}(A+1) \frac{\delta}{\beta} \sinh (\delta \tau) J_{0}\left(\frac{\delta}{\beta} x\right) .
\end{aligned}
$$


In these equations, we denote by $J_{1}\left(\frac{\delta}{\beta} x\right)$ and $J_{0}\left(\frac{\delta}{\beta} x\right)$ the Bessel functions of the first kind. Equations (16), given that disturbance $\hat{V}_{\varphi}=0$ as a result of the second equation, have the following presentation

$$
\begin{aligned}
& \frac{\partial \xi_{r}^{2}}{\partial \tau^{2}}-\frac{1}{x^{3}} \rho=-\frac{d p}{d x}, \\
& \rho+\left(\frac{\partial \xi_{r}}{\partial x}+\frac{\xi_{r}}{x}\right)=0, \\
& p+\frac{1}{x^{3}} \xi_{r}-\frac{\gamma}{2 x^{2}}\left(\frac{\partial \xi_{r}}{\partial x}+\frac{\xi_{r}}{x}\right)=0 .
\end{aligned}
$$

Substituting Eqs. (24) and (25) into Eq. (23) we obtain, as before, the single equation

$$
\frac{\partial^{2} \xi_{r}}{\partial \tau^{2}}=-\frac{\gamma}{2 x^{2}}\left[\frac{\partial^{2} \xi_{r}}{\partial x^{2}}-\frac{1}{x} \frac{\partial \xi_{r}}{\partial x}+\left(\frac{8}{\gamma}-3\right) \frac{1}{x^{2}} \xi_{r}\right] .
$$

Separating the variables, assuming that $\xi_{r}=S(\tau) \mathcal{F}(x)$, we obtain the system

$$
\begin{aligned}
& \frac{d^{2} S}{d \tau^{2}}-\delta^{2} S=0 \\
& \frac{d^{2} \mathcal{F}}{d x^{2}}-\frac{1}{x} \frac{d \mathcal{F}}{d x}+\frac{\mathcal{F}}{x^{2}}\left(\frac{8}{\gamma}-3\right)+\frac{2 \delta^{2}}{\gamma} x^{2} \mathcal{F}=0
\end{aligned}
$$

By solving both equations, we find

$$
\begin{aligned}
\xi_{r} & =C_{2} \sinh (\delta \tau) x \mathcal{N}_{q}\left(\frac{\delta}{\sqrt{2} \gamma} x^{2}\right) \\
p & =C_{2} \sinh (\delta \tau)\left[\frac{1}{x^{2}}(\gamma-1) \mathcal{N}_{q}\left(\frac{\delta}{\sqrt{2} \gamma} x^{2}\right)\right. \\
& \left.+\frac{\delta \gamma}{\sqrt{2 \gamma}} \mathcal{N}_{q}^{\prime}\left(\frac{\delta}{\sqrt{2} \gamma} x^{2}\right)\right]
\end{aligned}
$$

where $q=\frac{2}{\gamma}-\frac{1}{2}$ and $\mathcal{N}_{q}(z)$ is the Bessel function of the second kind, and the prime denotes the derivative with respect to the full argument $\frac{\delta}{\sqrt{2} \gamma} x^{2}$. Equating the values of $\xi_{r}$ and $p$ at the inner and outer sides of the cylinder at $x=1$, from Eqs. (22) and (27) we find

$$
\begin{aligned}
& C_{1} \sinh (\delta \tau) J_{1}\left(\frac{\delta}{\beta}\right)=C_{2} \sinh (\delta \tau) \mathcal{N}_{q}\left(\frac{\delta}{\sqrt{2} \gamma}\right), \\
& C_{1} \sinh (\delta \tau) \frac{\gamma}{2}(A+1) \frac{\delta}{\beta} J_{0}\left(\frac{\delta}{\beta}\right)= \\
& C_{2} \sinh (\delta \tau)\left\{\mathcal { N } _ { q } ( \frac { \delta } { \sqrt { 2 } \gamma } ) \left[(\gamma-1) \mathcal{N}_{q}\left(\frac{\delta}{\sqrt{2} \gamma}\right)\right.\right. \\
& \left.\left.+\frac{\delta \sqrt{\gamma}}{\sqrt{2}} \mathcal{N}_{q}^{\prime}\left(\frac{\delta}{\sqrt{2} \gamma}\right)\right]\right\} .
\end{aligned}
$$

Therefore,

$$
\begin{aligned}
& C_{2}=\frac{C_{1} J_{1}\left(\frac{\delta}{\beta}\right)}{\mathcal{N}_{q}\left(\frac{\delta}{\sqrt{2} \gamma}\right)}, \\
& \frac{(A+1)}{2 \beta} \delta \frac{J_{0}\left(\frac{\delta}{\beta}\right)}{J_{1}\left(\frac{\delta}{\beta}\right)}=1+\frac{\delta}{\sqrt{2} \gamma} \frac{\mathcal{N}_{q}^{\prime}\left(\frac{\delta}{\sqrt{2} \gamma}\right)}{\mathcal{N}_{q}\left(\frac{\delta}{\sqrt{2} \gamma}\right)} .
\end{aligned}
$$

It should be noted that because the jet moves upward in the chromosphere, its various parts will expand less or more, depending on the time they spend in the vortex layer. Thus, the upper portion of the vortex expands to a larger value than the lower, since due to the upward movement it will be in the vortex layer longer. To evaluate this tube's expansion, we use Eq. (22) for $x=1$ (surface of the tube):

$$
\xi_{r}=C_{1} \sinh (\delta \tau) J_{1}\left(\frac{\delta}{\beta}\right) \rightarrow \sinh (\delta \Omega t) J_{1}\left(\frac{\delta}{\beta}\right)
$$

We solved Eq. (28) numerically. The solution shows that the dependence of roots, $\delta$, as a function of $\Omega$, is intricate. For example, for the following parameters:

$$
\begin{aligned}
& \gamma=1.4, a=10^{7} \mathrm{~cm}, \quad \rho_{e 0}=10^{-13} \mathrm{~g} \mathrm{~cm}^{-3}, \\
& \mu=\frac{\rho_{i 0}}{\rho_{e 0}}=100, \quad B_{z}=B_{0}=1 \mathrm{G}, \quad \Omega=0.15 \mathrm{~s}^{-1} .
\end{aligned}
$$

Then, using Eqs. (??) and (21) we obtain $A=0.35368$, $\beta=0.077$, and by solving the second of Eqs. (28), finally we get $\delta \approx 0.18$. Now we are ready to analyse dependences in Eq. (29). Assuming that the characteristic time $t^{*}=10 \mathrm{~s}$, we obtain $\delta \Omega t^{*}=0.2711<1$. Therefore, we can apply the well-known expansion

$$
\sinh (x)=x+\frac{1}{6} x^{3}+O\left(x^{5}\right)
$$

and finally, passing to dimensional quantities using Eq. (??), we obtain the dependence $\xi_{r}(t)$ in the form

$$
\xi_{r} \approx a \cdot \sinh (\delta \Omega t) \approx 0.027 a t\left(1+0.00012 t^{2}\right), t \leq 10 \mathrm{~s} .
$$

Above, we took $t^{*}=10 \mathrm{~s}$ for the following reasons. Assuming that the thickness of the vortex layer ("vortex height') is $300 \mathrm{~km}$, and the speed of lifting of the modelli$\mathrm{ng}$ cylinder is $30 \mathrm{~km} / \mathrm{s}$, we get that the time of the passage through the layer for some of the cylinder cross section is just equal to $10 \mathrm{~s}$.

Therefore, the modeling cylinder will expand over time and we conclude that the jet as it is raised should take the form of a truncated cone with the upper base larger than its lower base. Of course, in this preliminary presentation, we are not yet concerned with a detailed analysis of the consequences of the equations obtained by us. This is a matter of subsequent work.

\section{DISCUSSION}

In this paper, we have considered the possible interaction of the solar jet and an external vortex in the solar atmosphere. Although this was not emphasised in our presentation, we proceeded from the assumption that such a vortex belongs to some horizontal vortex flow. In our opinion, this can ensure the formation of vortices in one place and the interaction with a jet in another and corresponds to the meaning of the term 'external vortex'. We note that the role of horizontal processes (along the surface of the photosphere) in the theory of 
jets was not given much importance. Only recently have there appeared works in which the horizontal dynamics of the chromosphere began to play an important role in the formation and movement of jets (e.g., [31]).

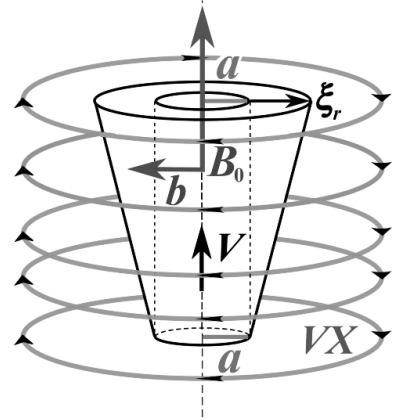

Fig. 3. Simplified model of the jet as a cylinder of magnetised plasma ( $a$ is a radius), which moves inside a flux tube with magnetic feld $\left(B_{0}\right)$ through the external vortex (VX) with a speed $\mathbf{V}$ in $z$ direction. Here $\mathbf{b}$ is the induced magnetic field, $\xi_{r}$ is a displacement of the lateral surface of the cylinder.

The consideration was necessarily schematic, given the complexity of the phenomenon itself. The authors understand that the use of the linear approximation is not sufficient, but it characterises the interaction picture qualitatively. To make a working model rather than a demonstration one, it is necessary first of all to take into account the internal structure of the jet and consider nonlinear effects. In Section II of our work, we used a number of assumptions in order to obtain an estimate of the thrust created by the vortex and applied to the jet. Obviously, in the linear approximation, we must use those parameters of the problem under which the relation is satisfied:

$$
\frac{\left(\mu_{0} \frac{\Omega^{2} a^{2}}{4 l}\right)}{g_{s}} \ll 1 .
$$

For example, for $a=1 \times 10^{7} \mathrm{~cm}, l=1 \times 10^{8} \mathrm{~cm}$ we obtain $\Omega \ll 0.33 \mathrm{~s}^{-1}$. If $a=3 \times 10^{7} \mathrm{~cm}, l=6 \times 10^{8} \mathrm{~cm}$, then the result is $\Omega \ll 0.27 \mathrm{~s}^{-1}$. Here we considered the most unfavorable case when $\mu_{0}=1$.

In Section III of the paper, we also used assumptions in order to obtain an estimate of the jet's deformation when it penetrates the vortex. The main condition for the fulfilment of the linear approximation formally has a simple form:

$$
\frac{\xi_{r}}{a} \ll 1
$$

However, in order to verify its fulfilment, it is necessary to obtain the value of the matching parameter, $\delta$, for the external and internal solutions, which itself is the solution of Eq. (28). It is more convenient to calculate numerically.

There is also a technical constraint due to the choice of a particular representation of the solution using the Bessel functions. Namely, solutions exist and are real if in Eq. (21)

$$
\beta^{2}=\frac{1}{\mu}\left[\frac{\gamma}{2}-A\left(1-\frac{\gamma}{2}\right)\right] \geq 0
$$

where $A$ is defined by Eqs. (9) and (??). After some calculations, we obtain the relation

$$
B_{0} \leq 20 a \Omega \sqrt{\rho_{0 e}} .
$$

Assuming that $a=3 \times 10^{7} \mathrm{~cm}, \Omega=0.16 \mathrm{~s}^{-1}$ we obtain $B_{0} \leq 300 \mathrm{G}$ for the lower chromosphere $\left(\rho_{0 e} \sim\right.$ $\left.10^{-11} \mathrm{~g} \mathrm{~cm}^{-3}\right), B_{0} \leq 30 \mathrm{G}$ for the middle chromosphere $\left(\rho_{e 0} \sim 10^{-13} \mathrm{~g} \mathrm{~cm}^{-3}\right)$ and $B_{0} \leq 3 \mathrm{G}$ for the upper chromosphere-transition layer $\left(\rho_{e 0} \sim 10^{-15} \mathrm{~g} \mathrm{~cm}^{-3}\right)$.

We emphasise that in this paper we set the task of understanding the main features of the interaction of solar jets and vortices in the atmosphere of the Sun. The values we obtained seem to be overestimated: taking into account the internal structure of the jets, the real atmosphere and non-linear effects will lead to an increase in the number of channels for the vortex' energy distribution. It is also necessary to understand what new features this factor can introduce into existing models of jets. For example, twisting of the tube, which, in particular, can occur due to the rapid rotation of the vortex, makes the picture much more meaningful. Then, in particular, we should pay attention to the possibility of resonance effects between the vortex's rotation speed and the parameters of the tube, which determine certain wave processes in it. It is too early to say that there is a detailed assessment of the role of this effect. The conditions under which the twisting becomes significant and goes beyond the limits of the solid-state approximation will be considered in the next paper.

\section{CONCLUSIONS}

(1) Most of the models currently under consideration in the literature assume the jets penetrate a calm solar atmosphere. Meanwhile, perturbations caused by the rise and fall of a multitude of spicules cannot fail to cause vortex flows in a differentially rotating solar atmosphere, as occurs in the case of hurricanes and tornadoes on the Earth.

(2) Interacting with a jet, a vortex in the solar atmosphere can create a thrust applied to the jet and directed upwards.

(3) The thrust complements the action of the initial pulse on the jet and the same elevation height can be achieved with lower initial velocities.

(4) Due to the action of the vortex, the jet raises both higher and during a longer time than in the case of the ballistic mechanism only.

(5) A jet, penetrating a vortex, can expand due to the centrifugal acceleration caused by the vortex.

(6) The simplest model of the phenomenon that has been developed nevertheless demonstrates the effect of the vortex structures on the flux tubes with magnetised plasma rising in the solar atmosphere. In order to improve the model, it is necessary, first of all, to take into account the internal structure of the jet. The results will be presented in our next paper. 


\section{Acknowledgements}

The authors thank Targeted Scientific Programme of the National Academy of Science of Ukraine on Space
Research for the partial support.

The authors are grateful to Dr. Viktor Fedun and Dr. Gary Verth (The University of Sheffield, UK) for the valuable discussions and advice.
[1] E. N. Parker, Nat. Astron. 4, 19 (2019); https://doi. org/10.1038/s41550-019-0985-7.

[2] T. S. Horbury, L. Matteini, D. Stansby, Mon. Not. R. Astron. Soc. 478, 1980 (2018); https://doi.org/10.1 093/mnras/sty953.

[3] J. J. González-Avilés, F. S. Guzmán, V. Fedun, G. Verth, Astrophys. J. 897, 153 (2020); https ://doi .org/10.384 $7 / 1538-4357 / a b 97 b 8$.

[4] S. Pucci et al., Astrophys. J. 776, 16 (2013); https : //doi.org/10.1088/0004-637X/776/1/16.

[5] B. De Pontieu, R. Erdélyi, I. De Moortel, Astrophys. J. Lett. 624, L61 (2005); https://doi.org/10.1086/4303 45.

[6] S. Wedemeyer et al., J. Phys. Conf. Ser. 440, 012005 (2013); https://doi.org/10.1088/1742-6596/ 440/1/012005.

[7] L. Yang et al., Astrophys. J. 852, 16 (2018); https:// doi .org/10.3847/1538-4357/aa9996.

[8] K. Murawski et al., Mon. Not. R. Astron. Soc. 474, 77 (2018); https://doi.org/10.1093/mnras/stx2763.

[9] J. J. Gonzalez-Aviles et al., Mon. Not. R. Astron. Soc. 484, 1936 (2019); https://doi.org/10.1093/mnras/st z087.

[10] E. Pariat et al., Astron. Astrophys. 596, A36 (2016); https://doi.org/10.1051/0004-6361/201629109.

[11] M. I. Stodilka, A. V. Sukhorukov, A. I. Prysiazhnyi, Kinem. Phys. Celest. Bod. 35, 231 (2019); https://doi. org/10.3103/S0884591319050040.

[12] R. G. Athay, The Solar Chromosphere and Corona: Quiet Sun (Springer Netherlands, 1975); https ://doi .org/10 .1007/978-94-010-1715-2.

[13] E. Pariat et al., Astron. Astrophys. 573, A130 (2015); https://doi.org/10.1051/0004-6361/201424209.

[14] I. P. Ladikov-Roev, in: Contemporary Mathematical Problems of Mechanics and Their Applications (Nauka, Moscow, 1989), p. 64.

[15] Y. P. Ladikov-Roev, A. A. Loginov, N. V. Maslova, O. K. Cheremnykh, Kosm. Nauka Tekhnol. 10, 128 (2004); https://doi.org/10.15407/knit2004.05.128.
[16] I. P. Ladikov-Roev, J. Automat. Inf. Sci. 44, 1 (2012) https://doi.org/10.1615/JAutomatInfScien.v44.i8.

[17] Y. P. Ladikov-Royev, S. O. Cheremnykh, V. A. Yatsenko, J. Automat. Inf. Sci. 45, 48 (2013); https://doi.org/ 10.1615/JAutomatInfScien.v45.i6.50.

[18] Y. P. Ladikov-Roev, A. A. Loginov, O. K. Cheremnykh, J. Automat. Inf. Sci. 46, 20 (2014); https://doi.org/ 10.1615/JAutomatInfScien.v46.i10.30.

[19] V. V. Akimenko, O. K. Cheremnykh, Probl. Upravlen. Inf. 2, 64 (2004).

[20] O. K. Cheremnykh, Russ. J. Nonlin. Dyn. 4, 417 (2008); https://doi .org/10.20537/nd0804003.

[21] S. Wedemeyer-Bohm, L. R. van der Voort, Astron. Astrophys. 507, L9 (2009); https://doi.org/10.1051/ 0004-6361/200913380.

[22] O. Steiner et al., Astrophys. J. 723, L180 (2010); https : //doi.org/10.1088/2041-8205/723/2/1180.

[23] S. Shelyag, P. Keys, M. Mathioudakis, F. P. Keenan, Astron. Astrophys. 526, A5 (2010); https://doi.org/ 10.1051/0004-6361/201015645.

[24] S. Wedemeyer-Bohm et al., Nature 486, 505 (2012); ht tps://doi.org/10.1038/nature11202.

[25] M. Murabito et al., Astron. Astrophys. 639, A59 (2020); https://doi .org/10.1051/0004-6361/202038360.

[26] V. M. Nakariakov, M. J. Aschwanden, T. V. Doorsselaere, Astron. Astrophys. 502, 661 (2009); https://do i.org/10.1051/0004-6361/200810847.

[27] E. A. Pashitskii, Plasma Phys. Rep. 40, 820 (2014); ht tps://doi.org/10.1134/s1063780x14090074.

[28] D. Kivotides, Phys. Rev. Fluids 3, 033701 (2018); https: //doi.org/10.1103/PhysRevFluids.3.033701.

[29] A. Saltelli, S. Funtowicz, Issues Sci. Technol. 30, 79 (2014).

[30] J. J. González-Avilés, F. S. Guzmán, V. Fedun, Astrophys. J. 83624 (2017); https://doi.org/10.384 $7 / 1538-4357 / 836 / 1 / 24$.

[31] J. Martínez-Sykora et al., Science 356, 1269 (2017); ht tps://doi.org/10.1126/science.aah5412.

\section{РОЗПОВСЮДЖДЕННЯ СОНЯЧНОГО АТМОСФЕРНОГО СТРУМЕНЯ У ВИХРОВОМУ ПОЛІ}

Ю. П. Ладіков-Роєв, С. О. Черемних, А. Д. Войцеховська, Ю. О. Селіванов Інститут космічних дослідженъ НАН України та ДКА Украӥни, Просп. Глушкова, 40, буд. 4/1, Київ, 03680, Украӥна

За припущенням наявності в сонячній атмосфері вихрового шару вивчено взаємодію хромосферних струменів з окремими вихорами. Хоча всі моделі припускають проникнення струменя в спокійну атмосферу, проте збурення, спричинені підйомом і падінням безлічі струменів, не можуть не спричинити вихрових потоків у диференціально обертальній сонячній атмосфері, як це відбувається під час ураганів і смерчів на Землі. Взаємодіючи зі струменем, вихор може створювати тягу, 
прикладену до струменя і направлену вгору. Тяга доповнює дію початкового імпульсу на струмінь, i такої самої висоти підйому можна досягнути за менших початкових швидкостей. Завдяки дії вихору струмінь піднімається як вище, так і протягом тривалішого часу, ніж, наприклад, лише у випадку з балістичним механізмом його старту. Струмінь, проникаючи через вихор, може розширюватися через відцентрове прискорення, викликане цим вихором. Обидва ефекти здатні змінювати характер руху струменів i, отже, - тонку структуру сонячного вітру.

Ключові слова: фізика Сонця, магнітна гідродинаміка, струмені, вихори 